\title{
PENINGKATAN KETERLIBATAN ORANG TUA DALAM PENDIDIKAN SEKS ANAK
}

\author{
Eny Purwandari ${ }^{1,}$ Abdul Kadir², ChlaraSinta Duri Kartika ${ }^{3}$, \\ Firda Shafira ${ }^{4}$ Ndaru Putri Yudhiarti ${ }^{5}$, Septina Nur Istiqamah ${ }^{6}$ \\ 1,2,3,4,5,6 Magister Psikologi, Universitas Muhammadiyah Surakarta \\ email: ep271@ums.ac.id; syamkar781@gmail.com
}

\begin{abstract}
The fulfillment of children sexual education is still ignore, the sex education for children is watched as something negative and still dificult to be educated to children. The parents has an important role for the children sexual education because the parents is the first teacher for the children. So that is the reason, there should have an effort to give an explaination to the children about the function of their sexual organs. Community service activities are divided into 5 stages which are attended by 80 parents (father and mother). The five stages are assessment, FGD, material I, material II, and closing. Parents take part in the activity enthusiastically. From this dedication activity the author is informed that self-position in social relations, parents are still reluctant to answer children's questions related to sexuality, a place to ask children about large percentage sexuality asking mothers because they feel closer, and sexual explanations are limited to physical differences between boy and girl. This form of community service is a much-needed parenting activity, because there is no school to be a parent, so it becomes an opportunity to be applied in the community
\end{abstract}

Keyword: Parent's role, Education, Children sexuality

\section{PENDAHULUAN}

Terkait dengan peran orang tua dalam komunikasi seksualitas dengan anak, penelitian (Lestari, 2007) mengungkapkan bahwa sikap ibu dalam komunikasi seksualitas dengan anak dapat dikategorikan menjadi: (1) memberikan penjelasan, (2) bingung dalam menjawab pertanyaan anak, (3) melarang anak untuk bertanya, (4) menunda jawaban dan menganggap anak akan tahu sendiri, dan (5) mengalihkan topik pembicaraan. Bila dilihat dari proporsinya masih lebih banyak ibu yang tidak memberikan penjelasan terhadap pertanyaan tentang seksualitas yang diajukan oleh anak daripada yang bersedia memberikan penjelasan. Kondisi tersebut dapat menjadi pendorong bagi anak untukmencari tahu sendiri dari sumbersumberlain yang memungkinkan untuk mengaksesnya (Lestari, 2013)
Penelitian Lestari (2011) mengungkapkan bahwa teman sebaya menjadi sumber informasi yang paling banyak dipilih oleh remaja laki-laki maupun remaja perempuan. Bila dicermati lebih lanjut terdapat perbedaan antara remaja lakilaki dan perempuan dalam memilih sumber informasi tentang seks. Remaja perempuan memilih teman $(41,6 \%)$ sebagai sumber pertama, berikutnya adalah orangtua $(14,2 \%)$, buku $(6,9 \%)$, internet $(6,5 \%)$, guru dan media $(3,4 \%)$, kakak (2,7\%), dan ahli (2,3\%). Pada remaja laki-laki pilihan untuk urutan pertama sumber informasi tentang seks juga teman, namun urutan berikutnya yang menonjol adalah internet. Urutan berikutnya adalah guru $(8,6 \%)$, media dan buku (masing-masing 3,3\%), orangtua $(1,9 \%)$, ahli $(1,5 \%)$ dan kakak (0.7\%). Pemilihan orangtua sebagai sumber informasi seks 
pada remaja perempuan relatif kecil, namun bila dibandingkan dengan pemilihan remaja laki-laki, remaja perempuan masih memiliki motivasi yang lebih besar daripada remaja laki-laki untuk mencari informasi tentang seks dari orangtua.

Peneltian yang dilakukan Kim (2007) Selain dari sisi anak, hambatan dalam komunikasi seksualitas juga dapat berasal dari sisi orang tua Seperti terungkap dalam penelitian orangtua dari keluarga Asia Amerika memilih mengomunikasikan nilainilai seksualitas pada anak secara implisit dan nonverbal.

Sedangkan hasil penelitian Lestari (2013) Komunikasi seksualitas orang tuaanak berperan penting dalam memberikan bekal informasi seksualitas pada anak dan membentuk perilaku seksual yang bertanggungjawab pada anak. Komunikasi seksualitas tersebut sebaiknya menekankan pentingnya nilai-nilai moral terkait seksualitas sebagaimana yang telah diajarkan dalam agama. Kelebihan komunikasi seksualitas orang tua-anak dibandingkan sumber informasi seksualitas lainnya adalah terjaminnya kesinambungan komunikasi yang terjadi antara orang tuaanak. Mengingat pentingnya peran orang tua sebagai pemberi informasi seksualitas bagi anak, sebaiknya orang tua menjalankan peran tersebut dengan baik agar anak tidak memenuhi rasa ingin tahunya tentang seksualitas ke sumber-sumber lain yang tidak dapat dipertanggungjawabkan kebenarannya. Terungkap bahwa komunikasi seksualitas yang terjalin antara orang tua dengan anak masih rendah. Bahkan masih ditemukan orang tua yang merasa tidak perlu membekali anak dengan pengetahuan seksualitas karena memandang anak akan tahu sendiri bila sudah besar (Lestari S., 2010).

Sedangkan hasil penelitian Kerry (2017) menyatakan mayoritas orang tua beanggapan bahwa pendidikan seksualitas pada anak sekolah dasar itu relevan dan penting. Pendidikan seksualitas seharusnya diberikan secara kolaboratif antara pihak sekolah dan keluarga. Namun beberapa keluarga mengakui bahwa sejauh ini beberapa topic terkait pendidikan seksual hanya bisa diberikan dirumah.

Jennife, (2017) Komunikasi keluarga tentang seks bisa melindungi remaja dari perilaku berisiko, seperti seks dini dan seks tanpa pengaman. sementara tidak ada perbedaan kelompok yang ditemukan untuk tanggapan terhadap orang tua sudut pandang Temuan studi menyoroti pentingnya seks program pendidikan yang mendukung seksualitas remaja komunikasi, terutama bagi siswa sekolah menengah.

Kesimpulannya, ada sejumlah aspek dan faktor (misalnya, sosio-ekonomi, genetik, psikologis, pendidikan, perkembangan, intra-individu, antar individu) yang dapat mempengaruhi keefektifan / keberhasilan program pendidikan seksual apare ntal sehubungan dengan Kesehatan seksual optimal anak-anak mereka. Banyak faktor ini serta hubungan di antara mereka masih memerlukan penyelidikan ilmiah yang cukup besar. Karena Pendidikan Seksualitas nampaknya merupakan konsep multi dimensi, kami menganggap bahwa pendekatan multidimensional dan interdisipliner serupa harus dilakukan saat merancang, menerapkan dan menafsirkan hasil dari program pendidikan seksual orang tua (Meda, 2015)

Hasil penelitian menunjukkan bahwa ada korelasi positif yang signifikan secara statistik antara tingkat perfeksionisme dan perfeksionisme seksual secara global. Hasil ini penting karena ada penelitian yang mengaitkan dimensi tertentu atau bentuk perfeksionisme maladaptif dengan faktor kerentanan psikopatologi. Mereka dapat membantu dalam menetapkan arah dan tingkat intervensi untuk mengelola kerentanan ini, mencegah atau mengurangi tekanan psikologis dan disfungsionalitas atau hanya mengembangkan potensi seseorang (Meda,2015).

Orangtua melaporkan peningkatan pemahaman tentang kurikulum pendidikan 
seksual dan kesadaran akan buku anakanak yang relevan, meningkatkan interaksi dengan anak-anak mereka mengenai topik pendidkan seksual dan beberapa efek positif pada pasangan dan sikap terhadap sekolah. Ada peningkatan kepercayaan diri dalam menangani masalah dalam kurikulum pendidikan seksual untuk orang tua yang berusia 8 sampai 10 tahun.

Hasil penelitian menunjukkan, dari sisi pendidikan dan pekerjaan, orangtua cukup berpotensi untuk banyak terlibat dalam pengasuhan anak. Keterlibatan orangtua baik di TK maupun di rumah sudah cukup baik, namun perlu ditingkatkan khususnya dalam melatih kemandirian keseharian anak di rumah dan kesediaan menjadi relawan di TK. Oleh karena itu perlu dipikirkan strategi yang sesuai agar orangtua lebih terlibat dalam pendidikan anaknya

Ada sejumlah besar anak sekolah yang melaporkan peningkatan pengetahuan kesehatan seksual di sekolah eksperimental. Hal ini menunjukkan bahwa fasilitator kesehatan memimpin program pendidikan seks lebih efektif dalam meningkatkan pengetahuan kesehatan seksual anak-anak sekolah (Amini, 2015).

\section{TUJUAN DAN MANFAAT}

Tujuan kegiatan pengabdiaan yang diikuti oleh 80 orang tua atau selaku wali murid siswa kelas 5 SD Birrul Walidain
Muhammadiyah Sragen ini adalah untuk: (1) Meningkatkan pengetahuan dalam memberikan edukasi mengenai seks pada anak yang sesuai, efektif dan efisien (2) memberi pemahaman bahwa pendidikan seks bukanlah hal yang tabu tetapi sebagai bentuk pembelajaran yang bersifat preventif agar anak bisa secara mandiri melindungi bagian personalnya.

Adapun manfaat yang didapatkan peserta dari mengikuti kegiatan ini antara lain: (1) Mempermudah orang tua dalam memberikan penjelasan yang berkualitas dan benar kepada anak tentang pendidikan seks; (2) ikut memanfaatkan dengan tepat hadirnya teknologi canggih seperti gadget dan fasilitas internet yang mendukung sebagai media pembelajaran untuk mencari referensi terkait; (3) bisa berperan sebagai fasilitator anak dengan memberikan rasa aman, nyaman dan menyenangkan ketika anak bertanya tentang pendidikan seks.

\section{METODE PELAKSANAAN KEGIATAN}

Mitra atau sasaran kegiatan pengabdian ini ialah orang tua atau wali murid SD Birrul Walidain Muhammdiyah Sragen. Jumlah orang tua yang terlibat sebanyak 80 orang tua. Tahapan kegiatan pengabdian ini mulai dari persiapan hingga kesimpulan dan sasaran yang selanjutnya mengikuti alur proses kerja sebagaimana digambarkan pada gambar dibawah ini

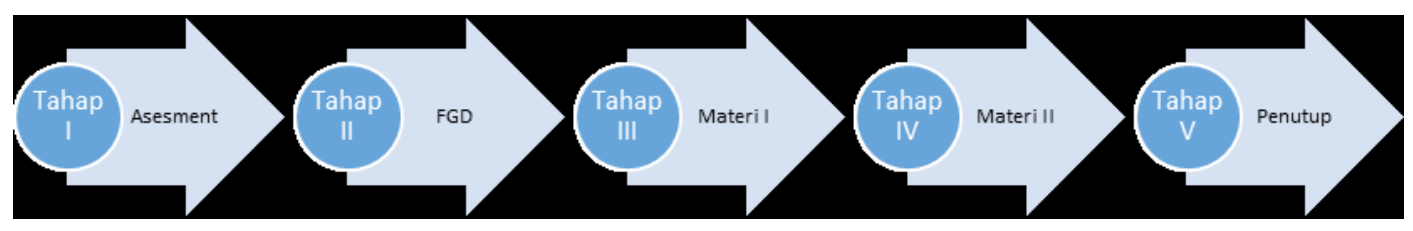

Gambar 1. Alur kerja kegiatan pengabdian masyarakat

Kegiatan pengabdian ini diawali dengan pembentukan tim pelaksana yang terdiri dari dosen dan mahasiswa mahasiswi Sekolah Pascasarjana Program Magister Psikologi Universitas Muhammadiyah Surakarta. Setelah tim pelaksana terbentuk, maka persiapan selanjutnya menentukan materi yang akan dibawakan sesuai tema yang diangkat. Rangkaian pengabdian masyarakat yang dilakukan adalah Asesment Seluk Beluk Pendidikan Seksual, Forum Group Discussion (FGD), Materi I, Materi II, Kesimpulan dan Penutup.

Tahap pertama, assessment dilakukan dengan pengisian form tentang seluk beluk seks dan pendidikan seks orang tua 
kepada anaknya. Pertanyaan yang di ajukan kepada responden tentang hal tersebut adalah (1) Apa yang anda ketahui tentang pendidikan seks untuk anak? (2) Ketika anak menanyakan hal berkaitan dengan seks, anak lebih sering bertanya pada ayah atau ibu? (3)
Bagaimana cara anda menjelaskan perbedaan seksualitas antara anak laki-laki dengan anak perempuan? (4) Bagaimana cara anda menjelaskan perbedaan seksualitas antara anak laki-laki dengan anak perempuan?
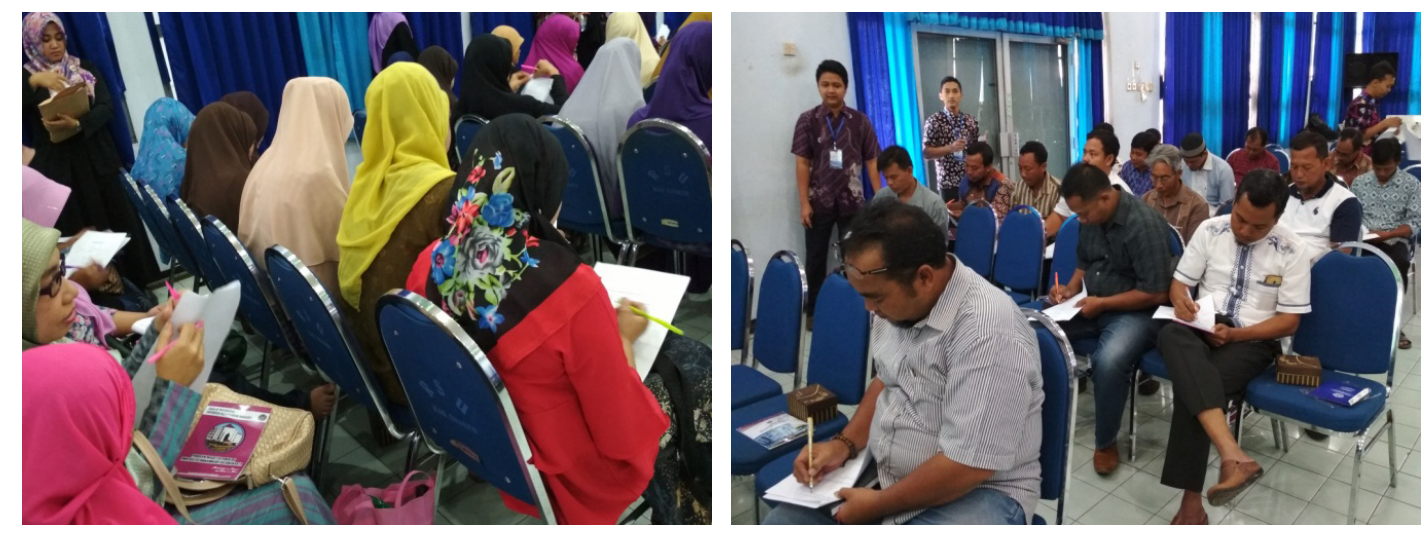

Gambar 2. Suasana saat pengisian form asesment

Tahap II dibuat kelompok-kelompok kecil yang berisikan 10-12 didampingi oleh satu fasilitator akan melakukan diskusi. Fasilitator membuka forum FGD dan membagikan angket yang berisikan pertanyaan yang gunanya untuk mengambil data tentang pendidikan seksual yang

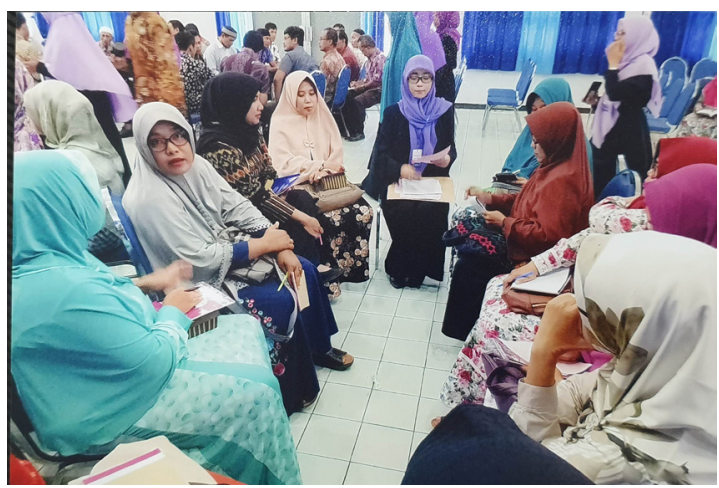

(a) diberikan orang tua kepada anak. Orang tua diminta untuk menjawab pertanyaan tersebut. Diskusi kelompok antar orang tua akan dipandu oleh fasilitator. Setelah sesi diskusi selesai fasilitator akan menarik kesimpulan besar dari hasil diskusi yang sudah dibahas per kelompok.

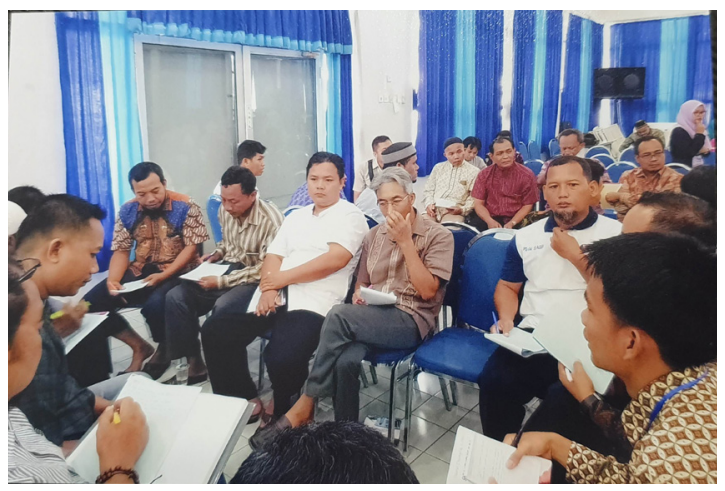

(b)

Gambar 3. Pelaksanaan FGD

Pelaksanaan FGD berlanjut dengan penyajian materi. Materi pertama tentang pendidikan seks dengan durasi 20 menit disampaikan oleh Sdri. Yuli Budiarti. Materi kedua disajikan oleh Dr. Eny Purwandari mengenai data-data tentang seksualitas dan respon orang tua. Data-data yang disajikan merupakan data dari putra putri orangtua yang hadir, sehingga menjadi bukti otentik relasi komunikasi tentang seksualitas orang tua-anak. Kegiatan ini diadakan pada tanggal 27 Januari 2018 bertempat di Gedung PMI Kabupaten Sragen, Jawa Tengah. 


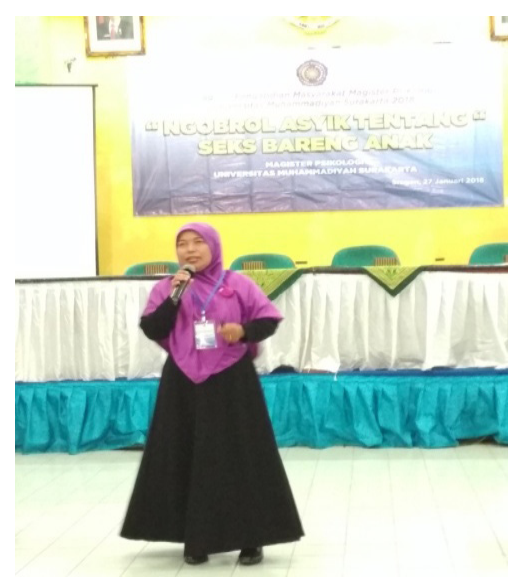

(a)

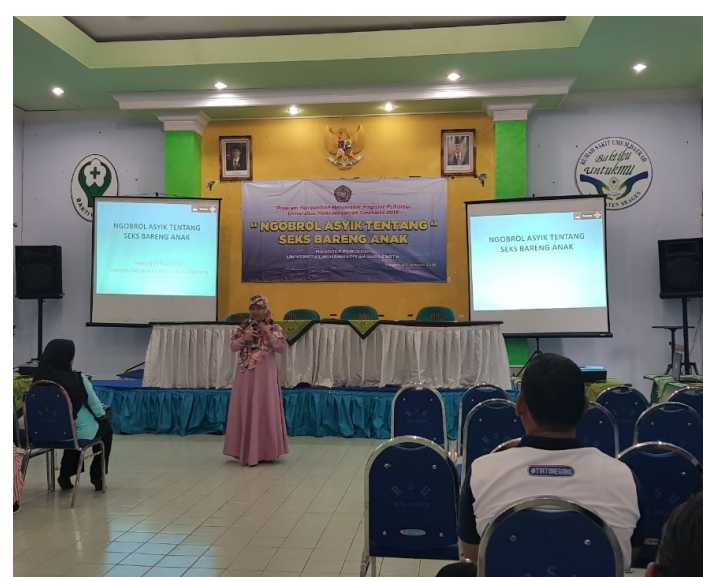

(b)

Gambar. 4 Presentasi materi I dan materi II

Setelah kegiatan inti selesai, di akhir sesi pengisi acara mengajukan beberapa pertanyaan rebutan yang ditujukan kepada semua peserta, hal ini dilakukan dengan tujuan seberapa besar antusias para peserta mengikuti kegiatan peserta yang bisa menjawab pertanyaan dengan tepat, lugas dan benar akan mendapat predikat peserta terbaik dan hadiah. Selain itu Kaprodi Magister Psikologi Universitas Muhammadiyah Surakarta juga menyerahkan kenangkenangan kepada pihak SD Birrul Walidain Muhammadiyah Sragen sebagai tanda terima kasih atas kerjasama pelaksanaan kegiatan pengabdian masyarakat.

Pada saat FGD terbangun suasana diskusi yang menarik mengenai hasil asesmen yang sudah diisi sebelumnya. Oleh karena itu kegiatan pengabdian ini menggunakan angket dengan pertanyaan terbuka. Model petanyaan terbuka dipilih agar dapat memahami pandangan responden tentang seksualitas anak. Salah satu bagian dari angket bertujuan mengungkap keterlibatan orang tua dalam mendidik seksualitas pada anak.

Hasil asesmen menjadi umpan balik dalam pelaksanaan FGD. Persepsi yang sudah dimiliki oleh setiap peserta dan hasil diskusi menjadi lengkap dengan sajian materi I dan materi II.

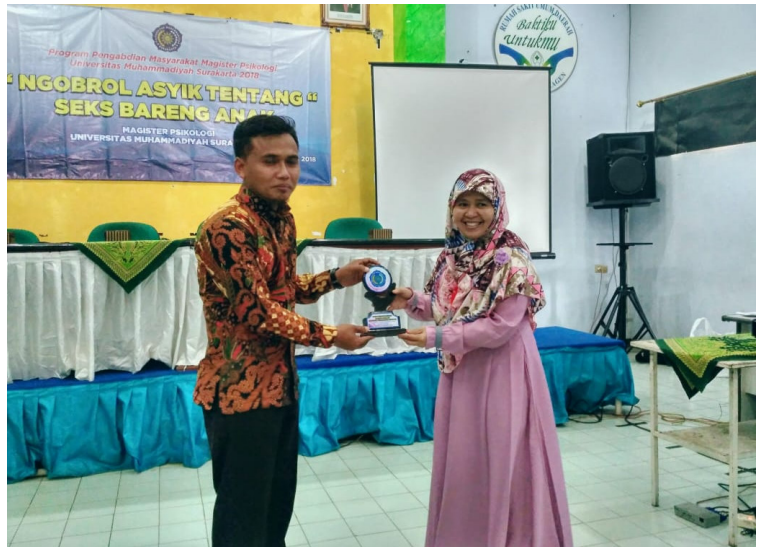

Gambar 5. Penyerahan kenang-kenangan

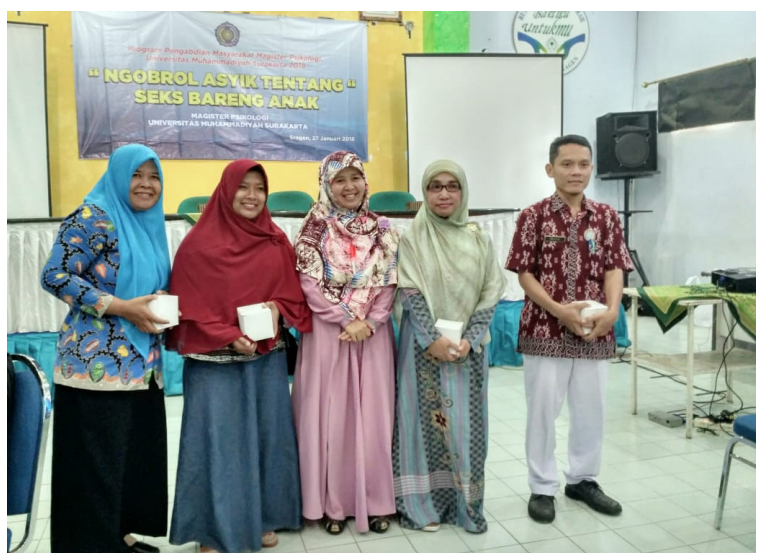

Gambar 6. Peserta terbaik berfoto bersama Kaprodi

\section{HASIL PELAKSANAAN KEGIATAN}

Secara etimologi, Istilah seksualitas belum ada padanan katanya dalam bahasa Indonesia, seksualitas berasal dari kata seks, yang berarti cirri-ciri anatomi biologi yang membedakan antara lelaki dan perempuan. 
Namun demikian, terma seksualitas dengan maknanya yang kompleks secara historis baru muncul pada awal abad ke-18. Seksualitas dimaknai sebagai konstruksi sosial tentang pengetahuan, norma, dan perilaku serta subjektivitas yang berkaitan dengan seks dan terkait erat dengan sistem kekuasaan pengetahuan. Seksualitas mencakup nilai atau norma, aturan-aturan, yang memberikan status dan peran, yang membatasi dan mengatur perilaku atau tindakam yang berkaitan dengan seks. Makna seksualitas adalah bagaimana suatu masyarakat memberikan arti terhadap pengalaman seksual yang secara nyata ada di masyarakat. Pemaknaan subjektif tidak dapat terlepas dari sistem kekuasaan yang memperkuat atau bahkan melegitimasi konstruksi pengetahuan, norma, dan perilaku seksualitas. Kebudayaan juga memiliki peran dalam penentuan makna seksualitas, yaitu kapan seseorang dapat memulai aktivitas seksual dan kapan menghentikannya, termasuk bagaimana mengekspresikannya. Seksualitas memiliki makna lebih luas dan mencakup tidak hanya seks, tapi juga gender dan persoalan relasi kuasa. Perbedaan paling penting antara seksualitas dengan seks dan gender terletak pada objek materialnya. Jika seks berkaitan dengan aspek fisik anatomic biologis, gender berhubungan dengan konstruksi sosial, dan seksualitas kompleksitas dari keduanya. Seks mendefinisikan jenis kelamin fisik hanya pada jenis laki-laki dan perempuan dengan pendekatan anatomis, sedangkan seksualitas merupakan konstruksi sosial terhadap entitas seks yang mengatur bodily functions (Rohmaniyah, 2017).

Olson \& Defrain (2011) menyatakan bahwa seksualitas merupakan aspek penting dalam kehidupan manusia, kesehatan, dan kebahagiaan. Seksualitas meliputi jenis kelamin, identitas dan peran gender, orientasi seksual, erotisme, kesenangan, keintiman, dan reproduksi. Seksualitas dialami dan diekspresikan dalam pikiran, fantasi, keinginan, kepercayaan, sikap, nila-nilai, perilaku, prakttek, peran, dan hubungan. Seksualitas dipengaruhi oleh interaksi niologis, psikologis, sosial, ekonomi, politik, budaya, etika, hukum, sejarah, agama, dan spiritual. Begitu banyak aspek yang mempengaruhi seksualitas namun tidak banyak yang mengungkap hal ini.

Sementara pengetahuan orang tua mengenai pendidikan seks untuk anak cukup mengetahuinya sebagai mana tabel 1 .

Tabel 1 : Pengetahuan tentang pendidikan seks untuk anak

\begin{tabular}{|c|c|c|}
\hline Kategori & Frekuensi & $\%$ \\
\hline - Batasan Pergaulan & 19 & 23.75 \\
\hline - Pemahaman Menjaga Diri & 17 & 21.25 \\
\hline $\begin{array}{l}\text { Perbedaan Karakteristik } \\
\text { Fisik Lk dan Pr }\end{array}$ & 16 & 20 \\
\hline $\begin{array}{l}\text { - Pendidikan Ilmiah dan } \\
\text { Agama }\end{array}$ & 6 & 7.5 \\
\hline - Hubungan Lawan Jenis & 4 & 5 \\
\hline • Hal Yang Tabu & 4 & 5 \\
\hline - Batasan Aurat & 3 & 3.75 \\
\hline - Pendidikan Akil Baliqh & 3 & 3.75 \\
\hline • Belum Tahu & 3 & 3.75 \\
\hline - Tidak Menjawab & 3 & 3.75 \\
\hline $\begin{array}{l}\text { - Pentingnya Pendidikan } \\
\text { Seks }\end{array}$ & 2 & 2.5 \\
\hline Jumlah & 80 & 100 \\
\hline
\end{tabular}

Berdasarkan tabel 1 dapat dicermati bahwa orang tua cenderung menjelaskan kepada anak yang berkaitan dengan posisi diri dalam relasi social. Hal ini menjadi salah satu bukti bahwa Indonesia adalah sebagai negara kolektivistik (Berry \& Portinga, 1999). Anak-anak lebih disiapkan secara social, namun belum cukup membawa bekal yang berupa pengetahun yang berkaitan dengan seksualitas.

Tabel 2 : Penjelasan seks pada anak

\begin{tabular}{lcc}
\hline \multicolumn{1}{c}{ Kategori } & Frekuensi & $\mathbf{\%}$ \\
\hline - Pernah & 46 & 57.5 \\
- Belum & 26 & 32.5 \\
- Tidak Menjawab & 8 & 10 \\
\hline Jumlah & 80 & 100 \\
\hline
\end{tabular}

Membicarakan seks pada anak sampai saat ini masih dianggap tabu oleh orang 
tua. Sehingga masih cukup besar prosentase orang tua yang belum menjelaskan tentang seks pada anak. Kondisi ini peran budaya sangat besar. Dimana pembahasan tentang seksual hanya milik orang dewasa, anakanak belum dianggap cukup umur. Selain itu, pengetahuan tentang seksual yang dimiliki orang tua masih terbatas pada norma social, sehingga yang muncul dengan penjelasan yang memakai perumpamaan yang mengaburkan konsep tentang sesual anak. Misalnya alat kelamin laki-laki disebut "burung" dan lain-lainnya.

Tabel 3. Cara orang tua memberi pendidikan seks pada anak

\begin{tabular}{lcc}
\hline \multicolumn{1}{c}{ Kategori } & Frekuensi & $\mathbf{\%}$ \\
\hline - Dengan cara & 21 & 26.25 \\
menjelaskan & 12 & 15 \\
- Cara diskusi & 9 & 11.25 \\
- Belum waktunya & 8 & 10 \\
- Belum mengetahui & 7 & 8.75 \\
- Penjelasan melaui media & 7 & 8.75 \\
- Tidak menjawab & 5 & 6.25 \\
- Belum pernah & 4 & 5 \\
- Cara mendongeng & 4 & 5 \\
- Cara bercerita & 3 & 3.75 \\
- Anak tidak bertanya & 3 & 3.75 \\
- Tidak paham dengan & 1 & 1.25 \\
$\quad$ bahasa anak & & \\
\hline Jumlah & 80 & 100 \\
\hline
\end{tabular}

Orang tua yang hadir pada acara pengabdian ini adalah orang tua dari anak usia kelas 5 Sekolah Dasar dengan rentang usia 10 - 11 tahun. Pada usia ini, menurut Piaget (Santrok, 20011) anak masih berada pada usia transisi antara operasional konkrit ke operasional formal. Pada fase ini penjelasan sangat diperlukan untuk membangun konsep. Namun konsep yang benar yang mudah diterima logika anak yang masih dominan melibatkan panca indera yang konkrit. Jadi orang tua harus hati-hati, cerdas dan pintar. Oleh karena itu komunikasi tentang seksual menjadi skill yang sangat dibutuhkan oleh orang tua. Orang tua yang mempunyai skill terlebih dahulu harus mempunyai pengetahuan tentang seks dengan baik.
Tabel 4 : Tempat bertanya seks anak pada orang

\begin{tabular}{lcc}
\multicolumn{3}{c}{ tua } \\
\hline \multicolumn{1}{c}{ Kategori } & Frekuensi & \% \\
\hline - Ibu & 57 & 71.25 \\
- Tidak jawab & 11 & 13.75 \\
- Keduanya & 7 & 8.75 \\
- Ayah & 5 & 6.25 \\
\hline Jumlah & 80 & 100
\end{tabular}

Pada table 4 menunjukkan bahwa ibu menjadi tempat bertanya anak tentang seksual dibandingkan bertanya pada bapak. Pada kondisi ini menunjukkan bahwa salah satu objek kelekatan anak adalah ibu (Cavendisk, Nielsen, \& Montague (2012). Jika anak tidak terbentuk kelekatan pada objek lekat yang baik dan tepat akan menjadikan anak mengalami gangguan perilaku. Jadi apabila anak menanyakan seks pada orang tua menjadi hal yang tepat. Tapi apabila $13.75 \%$ anak tidak menjawab berarti anak masih mengalami kebingungan dan mencari informasi tentang seks di tempat yang lain dan kurang percaya pada orang tua. Dari kegiatan pengabdian ini juga dikuatkan di table 5.

Tabel 5 : Alasan tempat bertanya anak pada orang tua

\begin{tabular}{lcc}
\hline \multicolumn{1}{c}{ Kategori } & Frekuensi & \% \\
\hline $\begin{array}{l}\text { Kedekatan dengan ayah/ } \\
\text { ibu }\end{array}$ & 60 & 75 \\
- Tidak menjawab & 15 & 18.75 \\
- Persamaan gender ayah/ & 3 & 3.75 \\
$\quad$ ibu & & \\
- Perbedaan karakteristik & 1 & 1.25 \\
$\quad \begin{array}{l}\text { fisik } \\
\text { - Anak tidak bertanya }\end{array}$ & 1 & 1.25 \\
\hline Jumlah & 80 & 100 \\
\hline
\end{tabular}

Orang tua menjadi tempat yang baik dan tepat untuk bertanya tentang seksual, selain kepada guru. Sumber informasi tentang seksual pada anak harus benar karena akan membentuk konsep tentang seksual sehingga tidak mengalami gangguan yang berkiatan dengan identitas dan peran jenis kelamin (Santrok, 2012). 
Tabel 6 : Cara orang tua menjelaskan perbedaan laki-laki dan perempuan

\begin{tabular}{|c|c|c|}
\hline Kategori & Frequensi & $\%$ \\
\hline - Menjelaskan ciri fisik & 20 & 23.75 \\
\hline - Tidak menjawab & 16 & 20 \\
\hline - Melalui media & 12 & 15 \\
\hline - Fungsi organ reproduksi & 10 & 12.5 \\
\hline - Belum menjelaskan & 5 & 6.25 \\
\hline $\begin{array}{l}\text { - Menjelaskan perbedaan } \\
\text { perilaku }\end{array}$ & 5 & 6.25 \\
\hline $\begin{array}{l}\text { Menjelaskan dengan } \\
\text { pendekatan agama }\end{array}$ & 4 & 5 \\
\hline - Dijelaskan di sekolah & 3 & 3.75 \\
\hline $\begin{array}{l}\text { Menjelaskan perbedaan } \\
\text { sifat laki-laki dan } \\
\text { perempuan }\end{array}$ & 2 & 2.5 \\
\hline $\begin{array}{l}\text { - Menjelaskan batasan } \\
\text { pergaulan }\end{array}$ & 1 & 1.25 \\
\hline $\begin{array}{l}\text { Menjelaskan cara } \\
\text { berpakaian }\end{array}$ & 1 & 1.25 \\
\hline $\begin{array}{l}\text { - Menjelaskan dampak } \\
\text { perilaku }\end{array}$ & 1 & 1.25 \\
\hline Jumlah & 80 & 100 \\
\hline
\end{tabular}

Pada table 5 menunjukkan bahwa orang tua sudah menjelaskan seksual pada anak dengan tahapan perkembangan kognitif yang sudah cukup sesuai, yaitu tahapan perkembangan operasional konkrit. Pada usia ini orang tua dituntut untuk mampu menjeaskan tentang seksualitas yang bisa ditangkap oleh panca indra anak, misalnya dengan gambar, tentunya yang sesuai dengan usianya, menjelaskan dengan bahasa ilmiah

Keterlibatan orang tua anak dalam pendidikan seks menjadi hal yang penting diketahui oleh orang tua. Pengetahuan orang tua tentang cara berkomunikasi tentang seksualitas pada anak, ketrampilan menyampaikan informasi yang benar tentang seksualitas, menghadapi keingintahuan anak yang berkaitan dengan identitas dan peran jenis kelamin, menjadi kebutuhan orang tua. Oleh karena itu parenting yang membahas tentang pendidikan seksualitas sejak dini menjadi urgent.

\section{KESIMPULAN DAN SARAN}

Secara keseluruhan kegiatan pengabdian masyarakat yang diadakan oleh sekolah pascasarjana Magister Psikologi Universitas Muhammadiyah Surakarta bekerjasama dengan SD Birrul Walidain Muhammadiyah Sragen berjalan lancar sesuai rencana yang diharapkan . Latar belakang pekerjaan serta usia dan pendidikan menjadikan adanya beragam respon yang menjadi bahan diskusi yang menarik. Animo yang besar kedatangan orang tua dalam kegiatan pengabdian masyarakat tersebut menjadi cerminan bahwasanya orang tua memiliki rasa curiousity tentang tema yang diusung dikarenakan hal tersebut berhubungan langsung dengan anak-anak yang notabene masih berada di usia belia. Para orang tua juga mengharapkan kegiatan-kegiatan sejenis dapat diadakan lagi dengan tema yang terkini sebagai sarana pembelajaran.

Diharapkan setelah selesai kegiatan ini para orang tua bisa menyampaikan, meluruskan dan mengaplikasikan langsung dalam kehidupan sehari-hari terkait dengan pendidikan seks yang selama ini masih banyak kesalahpahaman atau menganggap itu sesuatu yang "memalukan", sesuatu yang "tabu" disampaikan kepada anak. Selain itu, diharapkan orang tua tidak bosan untuk mencari referensi yang disertai dengan penjelasan ilmiah bukan sekedar pendapat sendiri atau asumsi yang bisa menyebabkan salah kaprah. Buatlah diskusi yang menyenangkan bersama anak melalui media bacaan baik cetak maupun elektronik agar anak bisa mencerna dengan mudah.

\section{PERSANTUNAN}

Kami ucapkan terimakasih kepada Pimpinan Universitas Muhammadiyah Surakarta yang telah memberikan pendanaan dalam kegiatan ini. Kami juga mengucapakan terimakasih kepada pihak pengelola SD Birrul Walidain Muhammadiyah Sragen yang telah berkenan menjadi mitra dalam pelaksanaan pengabdiaan ini serta mahasiswa Magister Sains Psikologi 2016 yang berkenan membantu terlaksananya kegiatan ini. Semoga kegiatan ini dapat memberikan kemanfaatkan yang berkelanjutan. 


\section{DAFTAR PUSTAKA}

Berry, J.W; Pootinga, Y.H; Segall, M.H dan Dasen, P.R. 1999. Psikologi Lintas Budaya : Riset dan Aplikasi. Terjemahan oleh PT. Gramedia Pustaka Utama. Jakarta : PT. Gramedia Pustaka Utama.

BIBLIOGRAPHY Alimmuha, M. (2013, April ). Melindungi Anak dari Konten Negatif Internet. Studi terhadap peramban Web Khusus Anak, SAWWA, p. Vol. 8 no 2 .

Amini, M. (2015 ). PROFIL KETERLIBATAN ORANG TUA DALAM PENDIDIKAN ANAK USIA TK. journal international, Vol. 10 no 1.

Cavendisk, W., Nielsen, A.L., \& Montague. M. (2012). Parent attachment, school commitment, and problem behavior trajectories of diverse adolescents. Journal of Adolescence, 35(6), 1629-1639. doi: 10.1016/j.adolescence. 2012.08.001

Jennifer, G. (2017). “We Talked About Sex."“No, We Didn't”: Exploring Parent Agreement About Sexuality Communication. International Journal, Vol. 0,1-15.

Kerry, R. (2017). Responsibilities, tensions and ways forward: parents' perspectives on children's sexuality education. International Journal Sex Eduacation, Vol. 12-27.

Kim, J. L. (2007). Silence speaks volumes: Parental sexual communication among. Journal of Adolescent Research, Vol. 22, 3-31. DOI: 10.1177/0743558406294916.

Lestari, S. \&. (2007). Sikap ibu terhadap pertanyaan anak tentang seksualitas. Psikologika, Vol. $12,147-155$.

Lestari, S. (2010). Youth courtship sexual behavior, exposure to pornography, and parental sexual communication. Anima, Vol. 25 (4),257-264.

Lestari, S. (2013). KOMUNIKASI SEKSUALITAS ORANG TUA-ANAK BERBASIS NILAI. Prosiding Seminar Nasional Parenting. Solo .

Lestari, S. S. (2011). Identifikasi kebutuhan informasi seksualitas pada remaja . Jurnal Ilmiah Psikologi, Vol. 5 (2), 180-188.

Meda V. Popa, A. S. (2015). Satisfaction and Communication in Couples of Parents and Potential Parents - Psychological Predictors and Implications for Sexuality. Interational Journal ScienceDirect, Vol 402-410.

Meda V. Popa, A. S. (2015). The Role of Parents in Shaping and Improving the Sexual Health of Children - Lines of Developing Parental Sexuality Education Programmes. International Journal, Vol. 395-401.

Olson, D.H., DeFrain, J., \& Skogrand, L. (2011). Marriages Familes: Intimacy, Diversity, and Strengths. Seventh edition. New York: The McGraw-Hill Companies, Inc.

Santrok, J.W. (2011). Perkembangan Anak Jilid 2 Edisi 7. Terjemahan Sarah Genis B. Jakarta : Erlangga. 